\title{
A STUDY OF THE COMBINATION OF MICROCRYSTALLINE CELLULOSE AND MANNITOL IN A CO-PROCESSED DRY BINDER AND IN A PHYSICAL MIXTURE FOR THE USE IN ORALLY DISINTEGRATING TABLETS
}

\author{
JITKA MUŽÍKOVÁ1*, ANDREA NOVOTNÁ' and MARTIN BARTOŠ² \\ 'Department of Pharmaceutical Technology, Charles University, \\ Faculty of Pharmacy in Hradec Králové, Czech Republic \\ ${ }^{2}$ Department of Analytical Chemistry, Faculty of Chemical Technology, \\ University of Pardubice, Czech Republic
}

\begin{abstract}
Avicel ${ }^{\circledR}$ HFE-102 is a co-processed dry binder containing $90 \%$ microcrystalline cellulose and $10 \%$ mannitol. This paper compares this co-processed dry binder and a physical mixture of related dry binders, microcrystalline cellulose (Avicel ${ }^{\circledR} \mathrm{PH}-102$ ) and mannitol (Pearlitol ${ }^{\circledR}$ 100SD) in the ratio of $9: 1$. Flow properties, compressibility, lubricant sensitivity, tensile strength, friability and disintegration time of tablets are evaluated. Compressibility is evaluated by means of the energy profile of compression process, and lubricant sensitivity by means of the lubricant sensitivity ratio. The results are also compared with the microcrystalline cellulose for direct compression Avicel ${ }^{\circledR} \mathrm{PH}-102$ alone. The flow properties of the co-processed dry binder Avicel ${ }^{\circledR}$ HFE-102 alone and the physical mixture were comparable. Avicel ${ }^{\circledR}$ HFE- 102 showed higher values of the energy of plastic deformation, tensile strength of tablets, and a markedly lower lubricant sensitivity and tablet friability than the physical mixture of dry binders. Addition of lubricants exerted different effects on the disintegration of tablets. The co-processed excipient Avicel ${ }^{\oplus}$ HFE-102 is suitable for the use in orally dispersible tablets.
\end{abstract}

Keywords: co-processed dry binder, Avicel HFE-102, energy profile of compression, tensile strength of tablets, lubricant sensitivity, time of disintegration

Oral tablets are the most common solid dosage form. Their disadvantages can be a delayed onset of drug effect and problematic administration to small children, seniors, and patients with swallowing difficulties. These disadvantages can be solved by tablets dispersible in the mouth (1-3).

Orally dispersible tablets (ODT) are solid single-unit dosage forms. After placing on the tong, they disintegrate during a few seconds without the need of swallowing, chewing and the aid of additional water (1-3). The European Pharmacopoeia requires for them a period of disintegration within three min (1). According to FDA and USP, the requirement for their disintegration is even stricter, i.e. within $30 \mathrm{~s}$ (4). Biological availability of some active ingredients administered in this way is higher because absorption already starts taking place in the oral cavity, pharynx or oesophagus. At the same time, the first-pass effect is reduced and the irritating effect of some drugs on the gastrointestinal tract is decreased $(5,6)$. ODTs are an alternative to the administration of classic tablets and capsules, combining the advantages of solid and liquid dosage forms primarily from the viewpoint of the exact dosing and rapid absorption $(2,3)$.

The preferred method of ODT production is direct compression (6). This procedure is very economical and productive, because laborious manufacture of granulates is not necessary. Advantages are easy implementation, use of a conventional manufacturing device, limited number of manufacturing steps, and a low production price. However, demanding requirements are imposed on the properties of the basic auxiliary substances for direct compression of the so-called dry binders, in particular from the viewpoint of flowability and compactibility. In directly compressible tableting materials, dry binders fulfil the role of both the filler and the binder (7). The latest prospective group of excipients are the so-called coprocessed dry binders, which are produced by the

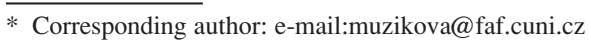


method of co-processing of a number of excipients, whose properties should complement each other. Coprocessed dry binders possess a number of advantages. In the course of co-processing there occur no chemical changes in the auxiliaries employed. Due to this, they are considered to be safe substances and it is not necessary to carry out further toxicological studies with them. All improved properties of co-processed dry binders, such as flowability and compactibility, result only from physical changes in excipients. With regard to the multifunctional properties of coprocessed dry binders, fewer excipients are sufficient for the manufacture of tablets, which markedly decreases production costs (8). Co-processed dry binders containing mannitol are often used in tablets which disperse in the mouth. These substances can include Avicel $^{\circledast}$ HFE-102, which contains $90 \%$ of microcrystalline cellulose and $10 \%$ mannitol $(9,10)$.

The paper aimed to compare the co-processed product Avicel ${ }^{\circledR}$ HFE-102 and a physical mixture of the related components (MCC -Avicel ${ }^{\circledR}$ PH-102 + $10 \%$ of mannitol - Pearlitol $\left.{ }^{\circledR} 100 \mathrm{SD}\right)$ from the viewpoint of flow properties, compressibility, tensile strength, friability and disintegration period of tablets. The results were also compared with microcrystalline cellulose alone for direct compression Avicel ${ }^{\circledR} \mathrm{PH}-102$.

\section{EXPERIMENTAL}

\section{Materials}

The study used the substances co-processed dry binder Avicel ${ }^{\circledR}$ HFE-102 (FMC Corporation,
USA), spray-dried mannitol Pearlitol ${ }^{\circledR}$ 100SD (Roquette, France), and microcrystalline cellulose Avicel $^{\circledR}$ PH-102 (FMC Corporation, USA), the lubricants being magnesium stearate (Acros Organics, USA) and sodium stearyl fumarate Pruv ${ }^{\circledast}$ (JRS Pharma, Germany). The model drug was ascorbic acid (Northeast General Pharmaceutical Factory, China).

\section{Preparation of tableting materials}

Altogether 12 tableting materials were used, the compositions of which are shown in Table 1. Multicomponent mixtures were prepared to the amount of $50 \mathrm{~g}$ in a mixing cube KB 15S (Erweka $\mathrm{GmbH}$, Germany), which rotated at a rate of 17 rotations/min. The physical mixture of Avicel PH-102 and Pearlitol 100SD was prepared by mixing for a period of $5 \mathrm{~min}$. More-than-two-component mixtures were prepared by graded mixing. In the formulations with the active ingredient, ascorbic acid was added to the dry binders for a period of mixing of 5 min. The lubricant magnesium stearate, or sodium stearyl fumarate was added as the last one for a period of mixing of $2.5 \mathrm{~min}$.

\section{Scanning electron microscopy (SEM)}

A compact scanning electron microscope VEGA3 SBU (Tescan, Brno, Czech Republic) was used to study the size, shape and structure of the particles of Avicel PH-102, Pearlitol 100SD, Avicel HF-102, and a physical mixture of Avicel PH-102 and Pearlitol 100SD in a ratio of $9: 1$. Experimental parameters were the acceleration voltage of $15 \mathrm{kV}$,

Table 1. Composition of tableting materials.

\begin{tabular}{|c|c|c|c|c|c|c|}
\hline $\begin{array}{c}\text { Tableting } \\
\text { material }\end{array}$ & $\begin{array}{c}\text { A HFE } \\
|\%|\end{array}$ & $\begin{array}{c}\text { A } 102 \\
\mid \% /\end{array}$ & $\begin{array}{c}\mathrm{A} 102+10 \% \mathrm{P} \\
/ \% /\end{array}$ & $\begin{array}{l}\mathrm{AA} \\
1 \% 1\end{array}$ & $\begin{array}{l}\text { Mgst } \\
1 \% /\end{array}$ & $\begin{array}{l}\text { Pruv } \\
1 \% /\end{array}$ \\
\hline F 1 & 100 & & & & & \\
\hline F 2 & & 100 & & & & \\
\hline F 3 & & & 100 & & & \\
\hline F 4 & 99 & & & & 1 & \\
\hline F 5 & 99 & & & & & 1 \\
\hline F 6 & & 99 & & & 1 & \\
\hline F 7 & & 99 & & & & 1 \\
\hline F 8 & & & 99 & & 1 & \\
\hline F 9 & & & 99 & & & 1 \\
\hline F 10 & 74 & & & 25 & & 1 \\
\hline F 11 & & 74 & & 25 & & 1 \\
\hline F 12 & & & 74 & 25 & & 1 \\
\hline
\end{tabular}

A HFE: Avicel HFE- 102; A 102: Avicel PH-102; P: Pearlitol 100SD; AA: Ascorbic acid; Mgst: magnesium stearate; Pruv: sodium stearyl fumarate 
a backscattered electron (BSE) detector and a low vacuum mode $\left(10 \mathrm{~Pa}, \mathrm{~N}_{2}\right)$. Samples were applied to an aluminium target coated with carbon adhesive tape (Pelco Tabs ${ }^{\mathrm{TM}}$, 12mm OD, Ted Pella, Inc., CA, USA). The target was then blown with compressed air and placed into the microscope chamber.

\section{Evaluation of flowability and Hausner ratio}

Flowability was tested on a Granulate Flow Tester GT (Erweka, Germany) according to the European Pharmacopoeia, 9 ${ }^{\text {th }}$ Edition (1). The weight of the powder was measured as that poured off after $3 \mathrm{~s}$ through a $15 \mathrm{~mm}$ orifice (speed of blade I). All measurements were repeated five times, and the values were averaged. Bulk and tapped densities were measured three times on a Tapped Density Tester (Erweka, Germany) by Method I according to the European Pharmacopoeia, 9 ${ }^{\text {th }}$ Edition (1). Hausner ratio was calculated as the ratio of the average value of tapped and bulk density (1).

\section{Preparation of tablets and energy evaluation of compression process}

Tablets were compressed on a T1 FRO 50 TH.A1K Zwick/Roell device (Zwick GmbH \& Co. KG, Germany) by means of a special die with a lower and an upper punch. Prior to compression, in the computer programme testXpert V 9.01 the required parameters were adjusted: the rate of compression of $40 \mathrm{~mm} / \mathrm{min}$, the preload $2 \mathrm{~N}$, and the rate of preload of $2 \mathrm{~mm} / \mathrm{s}$. The compression forces for the dry binders alone were $2,2.5$ and $3 \mathrm{kN}$. The mixtures with the lubricants and the active ingredient were compressed at $3 \mathrm{kN}$. The tablets were cylindrical without facets and had a diameter of $13 \mathrm{~mm}$ and weight of $0.5 \pm 0.001 \mathrm{~g}$. In each compression force, 26 tablets were compressed, 10 tablets were subsequently used for the strength test, 10 tablets for the friability test and 6 tablets for the test of disintegration time. The press controlling programme testXpert V 9.01 (Zwick GmbH \& Co. KG, Germany) quantified the parameters of the "force-displacement" record during tablet preparation. Evaluated parameters were $\mathrm{E} 1$ - precompression energy [J], E2 - energy of plastic deformation [J], E3 - energy of elastic deformation $[\mathrm{J}]$, Emax $(\mathrm{E} 1+\mathrm{E} 2+\mathrm{E} 3)$ - total energy $[\mathrm{J}]$, and $\mathrm{Pl}-$ plasticity [\%] $(11,12)$. Plasticity [\%] was calculated by means of equation (Eq. 1):

$$
\mathrm{Pl}=100 \mathrm{E}_{2} /\left(\mathrm{E}_{2}+\mathrm{E}_{3}\right)
$$

Evaluation of compactibility and lubricant sensitivity of dry binders

Compactibility was evaluated using the tensile strength of tablets. The tensile strength of tablets was evaluated in 10 tablets of each compression force, at least $24 \mathrm{~h}$ after their compression. Using a Tablet Tester M8 (Dr. Schleuniger Pharmatron AG, Switzerland), the height, diameter, and subsequently destruction force in $\mathrm{N}$ of tablets were measured. Tensile strength of tablets was calculated by means of the following equation (Eq. 2) according to Fell and Newton (13):

$$
P=2 F /(\pi d h)
$$

$P[\mathrm{MPa}]$ is tensile strength of tablets, $F[\mathrm{~N}]$ is destruction force, $d[\mathrm{~mm}]$ is diameter of tablets, and $h[\mathrm{~mm}]$ is height of tablets.

The lubricant sensitivity of dry binders was evaluated for the compression force of $3 \mathrm{kN}$ by the lubricant sensitivity ratio (LSR), which is calculated according to the equation (Eq. 3) (14):

$$
\mathrm{LSR}=(\mathrm{Csu}-\mathrm{Csl}) / \mathrm{Csu}
$$

Csu is the strength of tablets without a lubricant and Csl is the strength of tablets with a lubricant.

The more the value of LSR approaches 1, the more the dry binder is sensitive to the addition of a lubricant.

\section{Evaluation of tablet friability}

The friability of tablets was evaluated in 10 tablets of each compression force using Friability tester (Sotax Switzerland). The tablets were dedusted prior to testing, accurately weighted and placed in the drum. The drum rotated 100 times. Then the tablets were removed, dedusted and accurately weighted (1). The values of friablity were calculated.

\section{Evaluation of disintegration time of tablets}

Disintegration time was always measured at least $24 \mathrm{~h}$ after compaction in 6 tablets of each test group after evaluation. The measurements were made on a device for testing the disintegration time of tablets Erweka ZT 301 (Erweka GmbH, Hausenstamm, Germany) using the method described in the European Pharmacopoeia, 9 ${ }^{\text {th }}$ Edition (1). The test was carried out without discs in a medium of purified water at a temperature of $37^{\circ} \mathrm{C} \pm 1^{\circ} \mathrm{C}$. The tablets were considered disintegrated at the moment when on the net of the tube there was no residue.

\section{Statistical processing of results}

The parameters of energy balance of the compression process were statistically evaluated by the program testXpert V 9.01 (Zwick GmbH \& Co. KG, Germany) directly during the compression process. The results of flow properties, tensile strength and disintegration time of tablets were statistically evaluated using the program Excel. Test ANOVA $(\alpha=$ 
0.05) was used for the testing of statistical significance.

\section{RESULTS AND DISCUSSION}

Co-processed dry binders are important excipients for the preparation of tablets by direct compaction. Very often they are employed for the manufacture of orodispersible tablets. One of these products can be Avicel HFE-102, which is compared in this paper with a physical mixture of corresponding components, i.e. microcrystalline cellulose and mannitol in a ratio of $9: 1$., The microcrystalline cellulose Avicel PH-102 and the spray-dried mannitol Pearlitol 100SD, with the average particle size similar to Avicel HFE-102, i.e. ca. $100 \mu \mathrm{m}$, were selected for the preparation of the physical mixture $(15,16)$. As a matter of interest, all results were also compared with the microcrystalline cellulose Avicel PH-102 alone. Furthermore, the tests included also the mixtures of dried binders with $1 \%$ of lubricants, viz. magnesium stearate and sodium stearyl fumarate, and subsequently also the tableting mate- rials with the model drug ascorbic acid and sodium stearyl fumarate. In all tableting materials flow properties, i.e. flowability, bulk and tapped density were tested. In addition, compressibility was evaluated by means of the energy profile of compaction process. Tablets were tested for tensile strength, disintegration period and friability. In the dry binder alone, also lubricant sensitivity was evaluated. Initially the dry binders alone were evaluated in all parameters. Tablets from them were compacted at compaction forces of 2, 2.5 and $3 \mathrm{kN}$. These compaction forces were selected in such a way so that tensile strength of tablets may correspond to the optimal range of tensile strength of $0.56-1.12 \mathrm{MPa}$ as much as possible (17). Tablets prepared from mixtures with lubricants and ascorbic acid were compacted by the highest employed compaction force of $3 \mathrm{kN}$, because a decrease in the strength of tables was assumed.

\section{SEM imaging}

Representative SEM images of Avicel PH-102, Pearlitol 100SD, Avicel HFE-102 and the physical
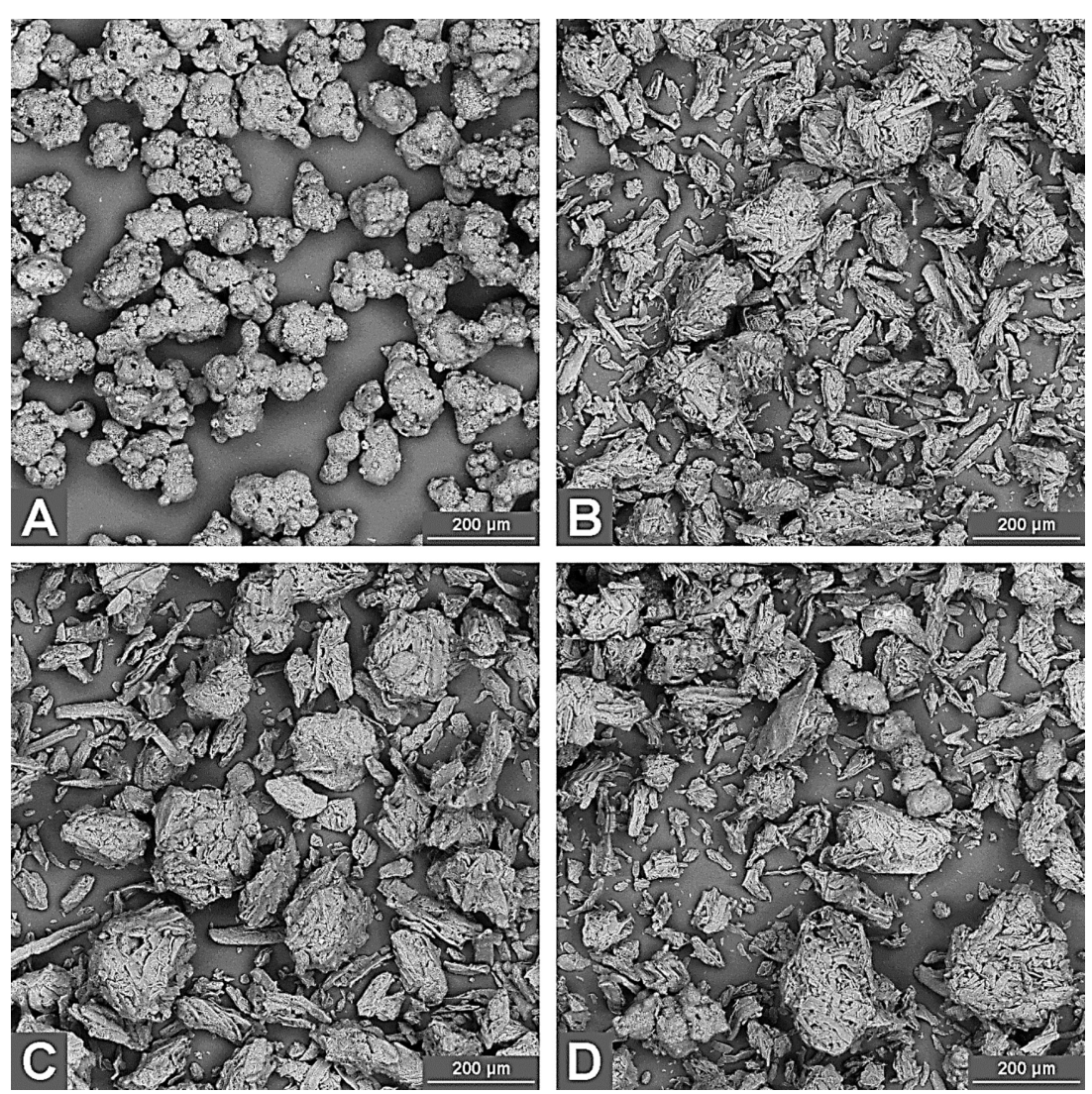

Figure 1. SEM images of Pearlitol 100SD (A), Avicel PH-102 (B), Avicel HFE-102 (C) and physical mixture of Avicel PH-102 and Pearlitol 100SD (D) 
Table 2. Evaluation of flow properties.

\begin{tabular}{|c|c|c|c|c|}
\hline $\begin{array}{c}\text { Tableting } \\
\text { material }\end{array}$ & $\begin{array}{l}\mathrm{M} / 3 \mathrm{~s} \pm \mathrm{SD} / \mathrm{g} / \\
\text { orifice } 1.5 \mathrm{~cm}\end{array}$ & $\begin{array}{c}\mathrm{BD} \pm \mathrm{SD} \\
/ \mathrm{g} / \mathrm{mL} /\end{array}$ & $\begin{array}{c}\mathrm{TD} \pm \mathrm{SD} \\
/ \mathrm{g} / \mathrm{mL} /\end{array}$ & $\mathrm{HR} \pm \mathrm{SD}$ \\
\hline $\mathrm{F} 1$ & $27.74 \pm 0.68$ & $0.37 \pm 0.01$ & $0.46 \pm 0.00$ & $1.25 \pm 0.00$ \\
\hline $\mathrm{F} 2$ & $19.60 \pm 1.54$ & $0.34 \pm 0.00$ & $0.43 \pm 0.00$ & $1.26 \pm 0.00$ \\
\hline F3 & $26.50 \pm 1.12$ & $0.37 \pm 0.00$ & $0.46 \pm 0.00$ & $1.23 \pm 0.00$ \\
\hline F4 & $31.42 \pm 1.56$ & $0.41 \pm 0.01$ & $0.50 \pm 0.01$ & $1.23 \pm 0.01$ \\
\hline F5 & $27.04 \pm 1.57$ & $0.39 \pm 0.00$ & $0.49 \pm 0.00$ & $1.25 \pm 0.00$ \\
\hline F6 & $24.62 \pm 1.19$ & $0.38 \pm 0.00$ & $0.48 \pm 0.00$ & $1.27 \pm 0.00$ \\
\hline F7 & $22.84 \pm 1.95$ & $0.36 \pm 0.01$ & $0.46 \pm 0.00$ & $1.27 \pm 0.00$ \\
\hline F8 & $39.56 \pm 0.10$ & $0.48 \pm 0.00$ & $0.54 \pm 0.00$ & $1.13 \pm 0.00$ \\
\hline F9 & $36.26 \pm 1.81$ & $0.44 \pm 0.00$ & $0.52 \pm 0.00$ & $1.18 \pm 0.00$ \\
\hline F10 & $27.50 \pm 1.17$ & $0.44 \pm 0.01$ & $0.54 \pm 0.00$ & $1.25 \pm 0.00$ \\
\hline F11 & $30.24 \pm 0.51$ & $0.46 \pm 0.00$ & $0.57 \pm 0.00$ & $1.24 \pm 0.00$ \\
\hline F12 & $27.48 \pm 1.34$ & $0.46 \pm 0.00$ & $0.57 \pm 0.00$ & $1.25 \pm 0.00$ \\
\hline
\end{tabular}

F: formulation; M: weight; BD: bulk density; TD: tapped density; HR: Hausner ratio; SD: standard deviation

mixture of Avicel PH-102 and Pearlitol 100SD (in the ratio of $9: 1$ ) are given in Figure 1. Pearlitol SD90 is composed of particles of a diameter of ca. $100 \mu \mathrm{m}$, which evidently developed by agglomerating smaller spherical particles (Fig. 1A). The dimensions of the largest agglomerations are up to $300 \mu \mathrm{m}$. In the compact/sintered surface of these particles there are orifices suggesting that inside the particles there are large pores. The particles of Avicel PH-102 (Fig. 1B) and Avicel HFE (Fig. 1C) cannot be distinguished visually, possessing identical size and structure. Their base is deformed flat rods of a length of ca. 100-150 $\mu \mathrm{m}$ and a width of ca. $25 \mu \mathrm{m}$, which are connected into disintegrating agglomerations of slightly oval shape of a size of $100-200 \mu \mathrm{m}$. In the mixture of Avicel PH-102 and Pearlitol 100SD it is possible to find, in the disintegrating particles of microcrystalline cellulose, compact aggregates of mannitol (Fig. 1D).

\section{Evaluation of flowability}

Flowability was tested by the method of determination of the weight poured off within a certain period of time, viz. $3 \mathrm{~s}$. An orifice of $1.5 \mathrm{~cm}$ and a mixing rate I of the stirrer were selected for measurements. The formulations with Avicel PH-102 were not poured through a smaller orifice and without the use of a stirrer; that is why the above-mentioned conditions of measurement were adjusted (18).

The results of flow properties are shown in Table 2. It follows from the results that the formulations with the physical mixture of dry binders with added lubricants (F8 and F9) poured best. The comparison of the dry binders alone (F1, F2 and F3) reveals that the worst flowability occurs in Avicel PH-102 (F2). No statistically significant difference $(\alpha=0.05)$ was found in the flowability of the remaining dry binders (F1 and F3). Lubricants improved the flowability of Avicel PH-102 (F6 and F7). In the case of tableting materials with ascorbic acid, the mixture with Avicel PH-102 (F11) poured best. There was no statistically significant difference $(\alpha=0.05)$ between the two remaining formulations (F10 and F12).

\section{Evaluation of bulk and tapped density}

The results of bulk and tapped density are shown in Table 2 . The formulations with the physical mixture of dry binders with added lubricants (F8 and F9) possessed the best flow from the viewpoint of the lowest value of Hausner ratio (1.13 and 1.18), therefore according to the European Pharmacopoeia, $9^{\text {th }}$ Edition, it was a good flow (1). The flow of Avicel PH-102 (F2) according to Hausner ratio, is only average. The flow of the remaining dry binders (F1 and F3) was adequate (1). Lubricants improved the flowability of PH-102 (F6 and F7), but the flow remained average (1). Tableting materials with ascorbic acid (F10 and F12) had the same Hausner ratio value, the flow was adequate (1).

\section{Energy profile of compression process}

The values of the energy profile of compression process are tabulated in Table 3. In the dry 
binders alone (F1, F2, F3), the energy profile of compaction process was evaluated against compression force $(2,2.5$ and $3 \mathrm{kN})$. Total energy of compression Emax increased with compression force, the highest values were shown by Avicel PH-102 $(\mathrm{F} 2)$, between the remaining dry binders (F1 and F3) there was no statistically significant difference $(\alpha=$ 0.05 ) in the compression forces of 2 and $2.5 \mathrm{kN}$. In the compression force of $3 \mathrm{kN}$ the physical mixture of dry binders (F3) showed a higher values of Emax. A comparison of the values for the energy of precompression E1 was also similar, excepting a statistically insignificant difference $(\alpha=0.05)$ between the values of this energy for F2 and F3 in the compression force of $2 \mathrm{kN}$ and statistically significantly higher values for F3 in the compression force of 2.5 $\mathrm{kN}$. The energy of precompression is consumed predominantly by friction. Energy of plastic deformation is important for the bonding and it is accumulated in tablets after the compression. Energy of plastic deformation E2 increased also with compression force and its highest values were exhibited by Avicel PH-102 alone, which is highly plastically deformable. Lower values were observed in Avicel HFE-102, which is composed of spray-dried particles, which are very suitable for the formation of

Table 3. Values of energy profile of compression and plasticity.

\begin{tabular}{|c|c|c|c|c|c|c|}
\hline $\begin{array}{c}\text { Tableting } \\
\text { material }\end{array}$ & $\begin{array}{c}\mathrm{CF} \\
/ \mathrm{kN} /\end{array}$ & $\underset{/ J /}{\operatorname{Emax} \pm S D}$ & $\begin{array}{l}\mathrm{E} 1 \pm \underset{/ J /}{\mathrm{SD}} \\
\mathrm{f}\end{array}$ & $\begin{array}{c}\mathrm{E} 2 \pm \mathrm{SD} \\
/ \mathrm{J} /\end{array}$ & $\begin{array}{c}\mathrm{E} 3 \pm \mathrm{SD} \\
/ \mathrm{J} /\end{array}$ & $\begin{array}{c}\mathrm{Pl} \pm \mathrm{SD} \\
/ \% /\end{array}$ \\
\hline \multirow{3}{*}{$\begin{array}{l}\text { A HFE } \\
(\mathrm{F} 1)\end{array}$} & 2 & $4.56 \pm 0.05$ & $1.706 \pm 0.041$ & $2.671 \pm 0.021$ & $0.179 \pm 0.003$ & $93.72 \pm 0.11$ \\
\hline & 2.5 & $6.09 \pm 0.05$ & $2.544 \pm 0.032$ & $3.316 \pm 0.025$ & $0.230 \pm 0.003$ & $93.52 \pm 0.07$ \\
\hline & 3 & $7.54 \pm 0.07$ & $3.299 \pm 0.054$ & $3.950 \pm 0.022$ & $0.292 \pm 0.007$ & $93.11 \pm 0.13$ \\
\hline \multirow{3}{*}{$\begin{array}{l}\text { A } 102 \\
(\mathrm{~F} 2)\end{array}$} & 2 & $4.72 \pm 0.06$ & $1.796 \pm 0.056$ & $2.725 \pm 0.018$ & $0.198 \pm 0.003$ & $93.23 \pm 0.09$ \\
\hline & 2.5 & $6.48 \pm 0.04$ & $2.756 \pm 0.031$ & $3.478 \pm 0.021$ & $0.250 \pm 0.003$ & $93.30 \pm 0.09$ \\
\hline & 3 & $8.20 \pm 0.06$ & $3.736 \pm 0.047$ & $4.159 \pm 0.031$ & $0.309 \pm 0.002$ & $93.07 \pm 0.08$ \\
\hline \multirow{3}{*}{$\begin{array}{c}\text { A } 102+10 \% \\
\text { P (F3) }\end{array}$} & 2 & $4.55 \pm 0.03$ & $1.779 \pm 0.034$ & $2.587 \pm 0.015$ & $0.182 \pm 0.004$ & $93.44 \pm 0.14$ \\
\hline & 2.5 & $6.13 \pm 0.06$ & $2.635 \pm 0.040$ & $3.256 \pm 0.029$ & $0.236 \pm 0.002$ & $93.24 \pm 0.08$ \\
\hline & 3 & $7.75 \pm 0.10$ & $3.573 \pm 0.094$ & $3.878 \pm 0.019$ & $0.295 \pm 0.003$ & $92.93 \pm 0.05$ \\
\hline F 4 & 3 & $7.63 \pm 0.07$ & $3.606 \pm 0.063$ & $3.731 \pm 0.038$ & $0.296 \pm 0.005$ & $92.66 \pm 0.15$ \\
\hline F 5 & 3 & $7.76 \pm 0.09$ & $3.730 \pm 0.088$ & $3.736 \pm 0.022$ & $0.291 \pm 0.005$ & $92.78 \pm 0.08$ \\
\hline F 6 & 3 & $8.08 \pm 0.17$ & $3.768 \pm 0.148$ & $4.007 \pm 0.034$ & $0.310 \pm 0.006$ & $92.82 \pm 0.11$ \\
\hline F 7 & 3 & $7.97 \pm 0.09$ & $3.676 \pm 0.073$ & $3.985 \pm 0.025$ & $0.307 \pm 0.004$ & $92.85 \pm 0.11$ \\
\hline F 8 & 3 & $5.86 \pm 0.05$ & $2.803 \pm 0.062$ & $2.808 \pm 0.027$ & $0.249 \pm 0.005$ & $91.86 \pm 0.18$ \\
\hline F 9 & 3 & $6.42 \pm 0.07$ & $3.313 \pm 0.069$ & $2.859 \pm 0.033$ & $0.243 \pm 0.008$ & $92.16 \pm 0.21$ \\
\hline F 10 & 3 & $5.80 \pm 0.11$ & $2.701 \pm 0.065$ & $2.838 \pm 0.049$ & $0.261 \pm 0.006$ & $91.57 \pm 0.20$ \\
\hline F 11 & 3 & $6.08 \pm 0.07$ & $2.748 \pm 0.056$ & $3.057 \pm 0.034$ & $0.273 \pm 0.003$ & $91.79 \pm 0.09$ \\
\hline F 12 & 3 & $5.75 \pm 0.03$ & $2.571 \pm 0.021$ & $2.919 \pm 0.025$ & $0.265 \pm 0.003$ & $91.68 \pm 0.08$ \\
\hline
\end{tabular}

A HFE: Avicel HFE-102; A 102: Avicel PH -102; P: Pearlitol 100SD; CF: compression force; Emax : total energy; E1: energy of pre-compression; E2 : energy of plastic deformation; E3: energy of elastic deformation; Pl: plasticity; SD: standard deviation

Table 4. Values of LSR.

\begin{tabular}{|c|c|c|}
\hline \multirow{2}{*}{ Dry binder } & \multicolumn{2}{|c|}{ LSR \pm SD } \\
\cline { 2 - 3 } & $1 \%$ Mgst & $1 \%$ Pruv \\
\hline A HFE & $0.11 \pm 0.02$ & $0.16 \pm 0.03$ \\
\hline A 102 & $0.32 \pm 0.02$ & $0.35 \pm 0.01$ \\
\hline A $102+10 \% \mathrm{P}$ & $0.71 \pm 0.02$ & $0.72 \pm 0.01$ \\
\hline
\end{tabular}

LSR: Lubricant sensitivity ratio; A HFE: Avicel HFE-102; A 102: Avicel PH -102; P: Pearlitol 100SD 


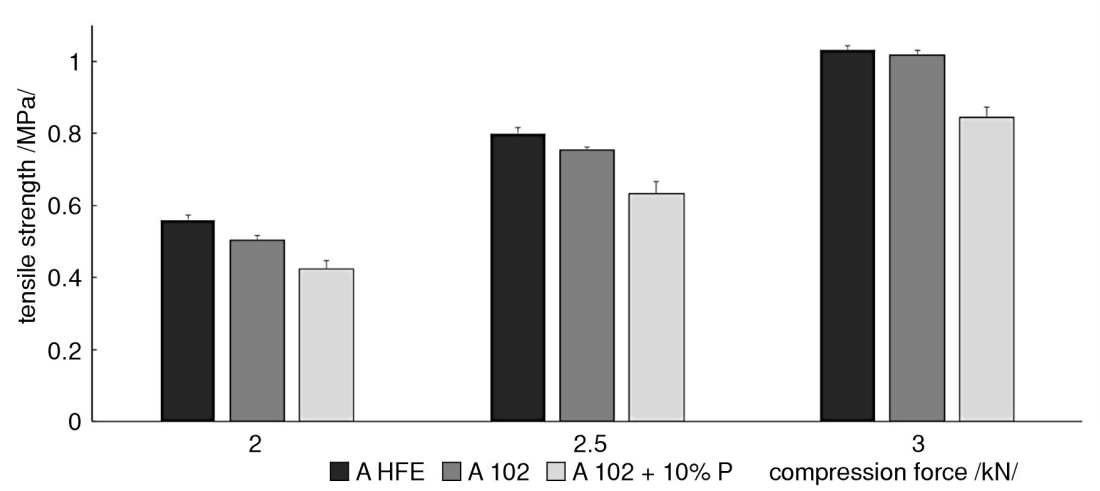

Figure 2. Tensile strength of tablets in function of compression force (mean $\pm S D ; n=10$ )

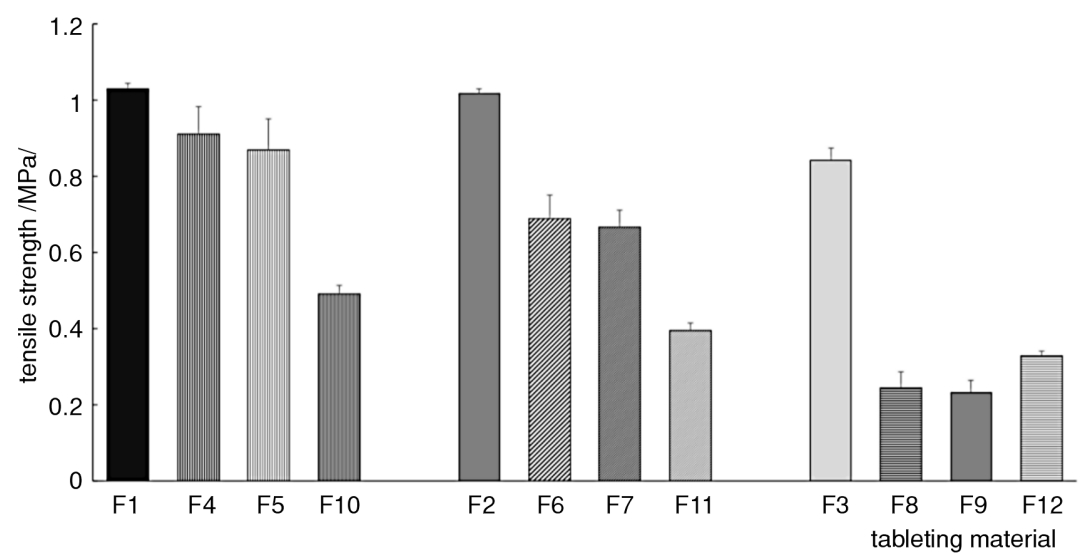

Figure 3. Tensile strength of tablets at the compression force of $3 \mathrm{kN}$ (mean $\pm \mathrm{SD} ; \mathrm{n}=10$ )

bonds, for which this energy is responsible. The lowest values of E2 were observed in the physical mixture of dry binders, in which mannitol need not be completely homogenously distributed as in the spray-dried product Avicel HFE-102 (10). Energy of elastic deformation E3 is energy of decompression, released after the compression. It increased also with compression force, the highest values being in the pure microcrystalline cellulose Avicel $\mathrm{PH}-102$, which is connected with its highly viscoelastic properties (7). Mannitol contained in the co-processed product and in the physical mixture decreased the energy of elastic deformation and there was no statistically significant difference $(\alpha=$ 0.05 ) in the values between the formulations F1 and F3. The higher the energy of decompression the lower the plasticity (Eq. 1) Plasticity slightly decreased with compression force and its values were balanced for the formulations with the dry binders (F1-F3) alone.
The observed effect of lubricants on the parameters of the energy profile of compression process at the compression force of $3 \mathrm{kN}$ is as follows. In Avicel HFE-102 due to the effect of added lubricants (F4, F5) there occurred an increase in the values of total energy of compression and the energy of pre-compression. In Avicel PH-102 (F6, F7) the values of total energy of compression were negligibly decreased and between the values of energy of precompression there was no statistically significant difference $(\alpha=0.05)$. In the case of the physical mixture of dry binders, due to the effect of lubricants the total energy and the energy of pre-compression were markedly decreased (F8 and F9). Energy of plastic deformation, which is important for the formation of bonds, was decreased due to added lubricants in the case of all dry binders. The energy of elastic deformation E3 was decreased due to added lubricants only in the case of the physical mixture of dry binders. The effect of lubricants on plasticity did 
not practically exert any influence, slightly lower values were observed in formulation F8. Ascorbic acid markedly decreased the values of total energy of compression, energy of pre-compression, energy of both plastic and elastic deformation, and it slightly decreased also the plasticity of tableting materials with all dry binders.

Tensile strength of tablets and lubricant sensitivity of dry binders

An important practical note is that the thickness is an significant parameter for tablets quality. Non-compliant deviations from industry standarts may indicate malformed tablet mass or pressure change during tableting. The tablets in this work were pressed individually using the said device, therefore the differences in tablet height were not high (see standard deviations in Table 5). Lubricants decrease the tablet height due to the interparticle friction decreasing. It leads to the better compressibility. Values of tablet height are reflected in the tensile strength of tablets (see Eq. 2).

Figure 2 presents the dependence of tensile strength of tablets on compression force for individual types of dry binders (F1, F2, F3). Tensile strength increased with compression force (Pearson correlation coefficient for Avicel HFE-102 and Avicel PH-102 is 0.9999, for the physical mixture of dry binders 1.0000), the highest being in tablets with Avicel HFE-102, the lowest then in tablets of the physical mixture of dry binders. Avicel-HFE-102 is a spray-dried product and the porous surface is more advantageous for multiple interparticle contacts (19). Mannitol is uniformly distributed within the microcrystalline cellulose matrix, as opposed to the physical mixture (10). Particles of Avicel HFE-102 can fragment into greater amounts of smaller pieces and new surfaces for bonds are created during the compression process (18).

After addition of lubricants to the individual dry binders, there was a decrease in tensile strength of tablets, which is represented in Figure 3. The lowest decrease in strength was recorded in the case of Avicel HFE-102, where mannitol bound by means of spray-drying to microcrystalline cellulose most probably blocks the binding sites for the lubricant. Much greater intervention in tensile strength was recorded in plastically deformable microcrystalline cellulose and the greatest decrease in strength occurred in the physical mixture of dry binders. It is therefore evident that there markedly occurred the plastic mechanism of compression of microcrys-

Table 5. Values of tablet height and friability.

\begin{tabular}{|c|c|c|c|}
\hline $\begin{array}{l}\text { Tableting } \\
\text { material }\end{array}$ & $\begin{array}{c}\mathrm{CF} \\
/ \mathrm{kN} /\end{array}$ & $\begin{array}{c}\text { Tablet height } \\
\text { /mm/ }\end{array}$ & $\begin{array}{c}\text { Friability } \\
1 \% /\end{array}$ \\
\hline \multirow{3}{*}{$\begin{array}{l}\text { A HFE } \\
(\mathrm{F} 1)\end{array}$} & 2 & $4.75 \pm 0.04$ & 1.22 \\
\hline & 2.5 & $4.45 \pm 0.01$ & 0.62 \\
\hline & 3 & $4.23 \pm 0.01$ & 0.59 \\
\hline \multirow{3}{*}{$\begin{array}{l}\text { A } 102 \\
(\mathrm{~F} 2)\end{array}$} & 2 & $5.10 \pm 0.04$ & 1.03 \\
\hline & 2.5 & $4.74 \pm 0.02$ & 0.54 \\
\hline & 3 & $4.48 \pm 0.02$ & 0.35 \\
\hline \multirow{3}{*}{$\begin{array}{c}\text { A } 102+10 \% \mathrm{P} \\
\text { (F3) }\end{array}$} & 2 & $4.88 \pm 0.03$ & - \\
\hline & 2.5 & $4.57 \pm 0.03$ & 6.36 \\
\hline & 3 & $4.32 \pm 0.01$ & 2.77 \\
\hline $\mathrm{F} 4$ & 3 & $4.06 \pm 0.04$ & 0.58 \\
\hline F5 & 3 & $4.08 \pm 0.04$ & 0.68 \\
\hline F6 & 3 & $4.32 \pm 0.04$ & 0.55 \\
\hline F7 & 3 & $4.35 \pm 0.03$ & 0.83 \\
\hline F8 & 3 & $3.99 \pm 0.06$ & - \\
\hline F9 & 3 & $4.04 \pm 0.04$ & - \\
\hline F10 & 3 & $3.74 \pm 0.02$ & 1.80 \\
\hline F11 & 3 & $3.93 \pm 0.03$ & 2.57 \\
\hline F12 & 3 & $3.87 \pm 0.02$ & 3.19 \\
\hline
\end{tabular}

A HFE: Avicel HFE-102; A 102: Avicel PH -102; P: Pearlitol 100SD 


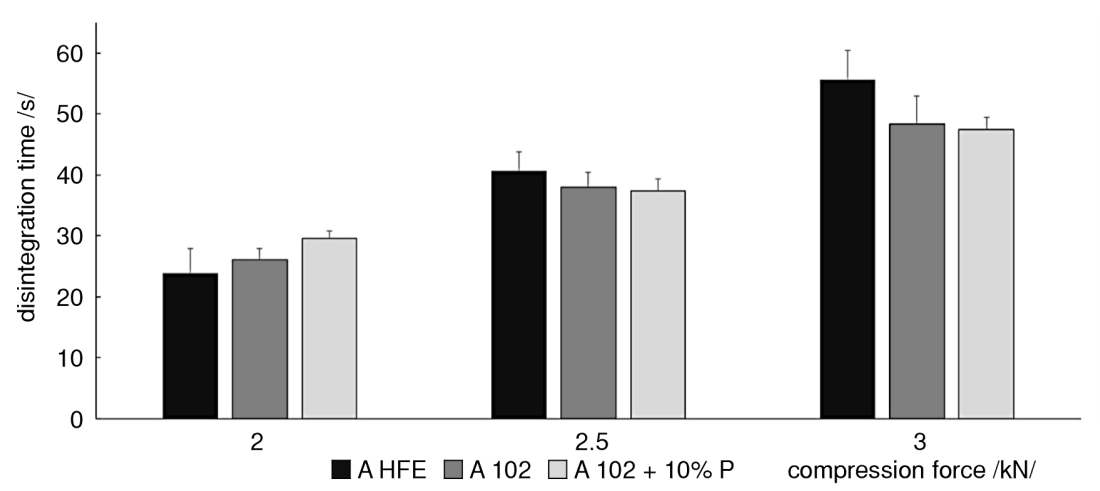

Figure 4. Disintegration time of tablets in function of compression force (mean $\pm \mathrm{SD} ; \mathrm{n}=6$ )

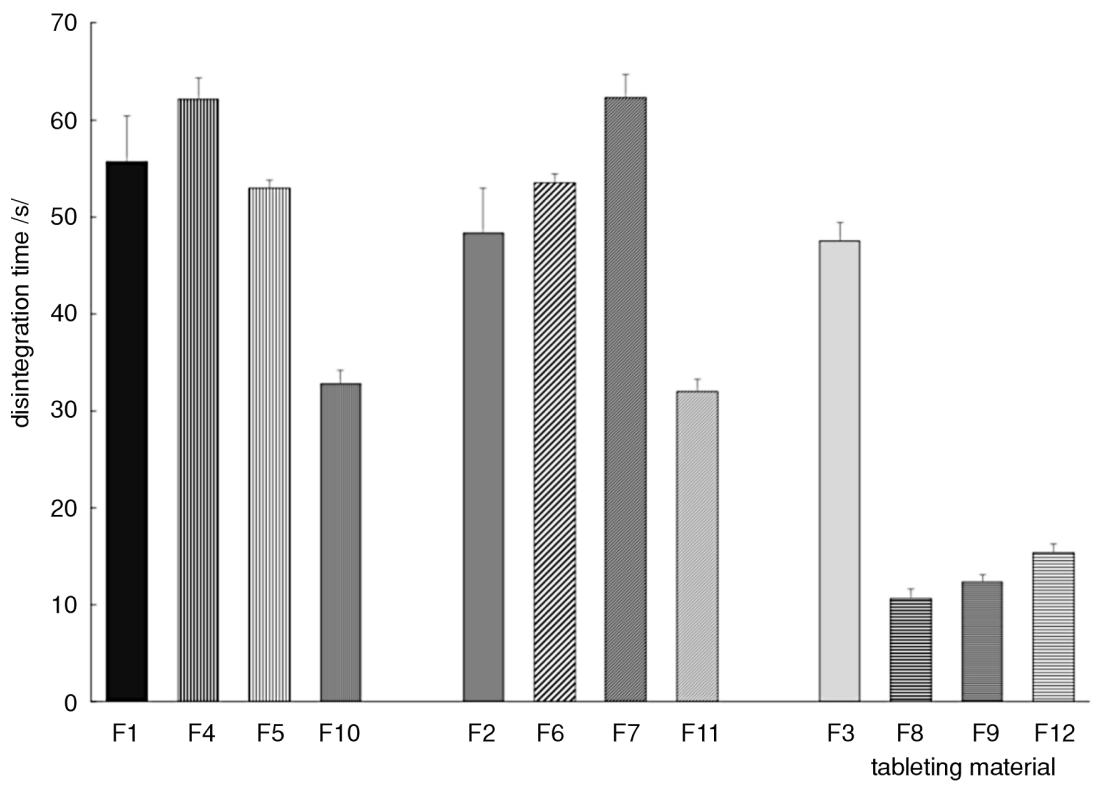

Figure 5. Disintegration time of tablets at the compression force of $3 \mathrm{kN}$ (mean $\pm \mathrm{SD} ; \mathrm{n}=6$ )

talline cellulose as well as mannitol (20-22), which in this case is not bound to MCC by the process of spray-drying. The sensitivity of dry binders to lubricants was also quantified by lubricant sensitivity ratio (LSR) values presented in Table 4. In this paper, the values of tensile strength, instead of crushing strength, are used for LSR calculation. Tensile strength is used to increase the precision of evaluation, as tablet dimensions are included in the calculations. The more the LSR value approaches 1 , the more the dry binder is sensitive to the lubricant (14). The above-mentioned values indicate a low sensitivity to added lubricants in Avicel HFE-102 and a high one in the physical mixture of Avicel PH102 and $10 \%$ Pearlitol 100SD. The sensitivity of Avicel PH-102 to the lubricant ranks it between the co-processed product and the physical mixture. The difference in the effect of the type of the lubricant is not statistically significant $(\alpha=0.05)$. Addition of ascorbic acid decreased the tensile strength of tablets in the case of Avicel HFE-102 and Avicel PH-102; in the physical mixture it was the opposite.

\section{Friability of tablets}

The values of friability of tablets are presented in Table 5. The values were satisfactory (to 1\%) in 
the case of Avicel HFE-102 (except compression force $2 \mathrm{kN}$ ) and Avicel PH-102 without and with lubricants as well. The values for tablets from the physical mixture of dry binders were unsatisfactory. Tablets from the physical mixture of dry binders (F3) compressed with the compression force of $2 \mathrm{kN}$ and tablets from this mixture with lubricants (F8 and F9) disintegrated during the test. Friability decreased with compression force. The results of friability for tableting materials with ascorbic acid were unsatisfactory but the lowest friability value (1.80) was measured for tablets with Avicel HFE102.

\section{Disintegration time of tablets}

Disintegration time of tablets against compression force for dry binders alone is represented in Figure 4. Disintegration time increased with compression force (Pearson correlation coefficient for Avicel HFE-102 is 0.9994, for Avicel PH-102 0.9992 and for the physical mixture of dry binders 0.9967 ), which is due to lower porosity of tablets and thus lower penetration of water into tablets (21). In the case of the compression force of $2 \mathrm{kN}$, the most rapid disintegration was observed in the tablets from Avicel HFE-102 and Avicel PH-102, whose disintegration time was within $30 \mathrm{~s}$. In the case of the compression forces of 2.5 and $3 \mathrm{kN}$, the longest disintegration time was observed in the tablets containing Avicel HFE-102. A shorter disintegration time without a statistically significant difference $(\alpha$ $=0.05$ ) was recorded in the tablets with Avicel PH102 and the physical mixture of dry binders. All tablets disintegrated within $1 \mathrm{~min}$. Addition of lubricants exerted different effects on the disintegration of tablets (Fig. 5). In Avicel PH-102 the disintegration period of tablets was prolonged by the action of lubricants, in Avicel HFE-102 it was prolonged only by addition of the more hydrophobic magnesium stearate. In the case of the physical mixture, the disintegration time was markedly shortened by the effect of lubricants because the strength of tablets was also markedly lower (Fig. 3). Addition of ascorbic acids markedly shortened the disintegration time due to its solubility in water and lower tensile strength of tablets (23).

\section{CONCLUSION}

The flow properties of the co-processed dry binder Avicel HFE-102 and the physical mixture of Avicel PH-102 and Pearlitol 100SD in the ratio of $9: 1$ were comparable. Addition of lubricants markedly improved the flowability and compressibility of the physical mixture of dry binders. Ascorbic acid equalized the values of flowability and compressibility of Avicel HFE-102 and the physical mixture. There was no statistically significant difference ( $\alpha=0.05$ ) between the values of total energy of compression for Avicel HFE -102 and the physical mixture in the compression forces of 2 and $2.5 \mathrm{kN}$. The energy of plastic deformation was higher in Avicel HFE-102 than in the physical mixture, which was also manifested by a higher strength of the tablets from Avicel HFE-102. Avicel HFE-102 showed much lower sensitivity to added lubricants than the physical mixture of dry binders. The period of disintegration of tablets with lubricants and ascorbic acid was shorter due to their low strength in the case of the physical mixture of dry binders. The longest disintegration period of tablets with Avicel HFE-102 was ca. $60 \mathrm{~s}$, which complies with the requirements of the European Pharmacopoeia, $9^{\text {th }}$ Edition, for orally dispersible tablets, which have to disintegrate within $3 \mathrm{~min}$. It means that the coprocessed excipient Avice ${ }^{\circledR}$ HFE-102 is suitable for the use in orally dispersible tablets which is in line with previously published literature $(9,10)$.

An important advantage of the co-processed dry binder Avicel HFE-102 versus the physical mixture of corresponding dry binder is better compressibility, compactibility, lower lubricant sensitivity and lower friability of tablets.

\section{Acknowledgements}

We would like to thank Roquette, FMC Corp. and JRS Pharma for providing of the excipients samples used in this study.

\section{Declaration of interest}

The authors report no conflicts of interest.

\section{REFERENCES}

1. European Pharmacopoeia $9^{\text {th }}$ ed. Strasbourg: Council of Europe, 2016.

2. Manivannan R.: IJPRD 1, 61 (2009).

3. Hirani J.J., Rathod D.A., Vadalia K.R.: TJPR 8, 161 (2009).

4. The United States Pharmacopeia 41: The national formulary 36. Rockville: The United States Pharmacopeial Convention, 2017.

5. Hahm H.A.: in Pharmaceutical dosage forms: Tablets. 3rd edn., Augsburger L.L., Hoag S.W. Eds., Vol. 2, p. 293, Informa Healthcare USA, 2008. 
6. Velmurugan S., Vinushitha S.: IJCPS 1, 1 (2010).

7. Carlin B.A.C.: in Pharmaceutical dosage forms: Tablets. 3rd edn., Augsburger L.L, Hoag S. W. Eds., Vol. 2, p. 173, Informa Healthcare USA 2008.

8. Gupta P., Nachaegari S.K., Bansal A.K.: in Excipient developement for pharmaceutical biotechnology, and drug delivery systems. Katdare K.A., Chaubal M.V. Eds., p. 109, Informa Healthcare USA 2006.

9. Jacob S., Shirwaikar A.A., Joseph A., Srinivasan K.K.: IJPS 69, 633 (2007).

10. Rojas J., Buckner I., Kumar V.: Drug Dev. Ind. Pharm. 38, 1159 (2012).

11. Ragnarsson G.:in Pharmaceutical Powder Compaction Technology. Alderborn G., Nyström Ch. Eds., p. 77, Marcel Dekker Inc., New York 1996.

12. Stamm A., Mathis C.: Acta Pharm. Technol. 22, 7 (1976).

13. Fell J.T., Newton J.M.: J. Pharm. Sci. 59, 688 (1970).

14. Bos C.E., Bolhuis G.K., Van Doorne H., Lerk C.F.: Pharm. Weekbl. Sci. 9, 274 (1987).
15. http://www.danisco.com/pharmaceuticals/pharmaceutical-products/avicelr-for-solid-doseforms/ (accessed on 03. 10. 2018).

16. https://www.pharmacompass.com/jAssets/pdf/ excipient/pearl.pdf (accessed on 03. 10. 2018).

17. Belousov V.A.: Khim. Farm. Zh. 10, 105 (1976).

18. Vodáčková B., Vraníková B., Svačinová P., Franc A., Elbl J. et al.: Biomed. Res. Int. 3, 1 (2018).

19. Michoel A., Rombaut P., Verhoye A.: Pharm. Dev. Tech. 7, 79 (2002).

20. Bolhuis G.K., de Waard H.: in Pharmaceutical powder compaction technology. 2nd edn., Çelik, M. Ed., p. 143, London: Informa Healthcare, 2011.

21. Thoorens G., Krier F., Leclercq B., Carlin B., Evrard B.: Int. J. Pharm. 473, 64 (2014).

22. Bolhuis G.K., Hölzer A.W.: in Pharmaceutical powder compaction technology. 2nd edn., Celik M. Ed., p. 205 London: Informa Healthcare, 2011.

23. Gupta A, Hunt R.I., Shah R.B., Sayeed V.A., Khan M.A.: AAPS Pharm. Sci. Tech. 10, 495 (2009).

Received: 24. 10. 2018 